\title{
PENGARUH SENYAWA PENGOTOR Ca DAN Mg PADA EFISIENSI PENURUNAN KADAR U DALAM AIR LIMBAH
}

\author{
Ign. Djoko Sardjono, Herry Poernomo \\ Puslitbang Teknologi Maju BATAN, Yogyakarta
}

\begin{abstract}
ABSTRAK
PENGARUH SENYAWA PENGOTOR Ca DAN Mg PADA EFISIENSI PENURUNAN KADAR U DALAM AIR LIMBAH. Telah dilakukan penelitian pengolahan air limbah uranium yang mengandung senyawa pengotor Ca dan Mg dengan pertukaran ion. Penelitian secara eksperimental ini dilakukan dengan menggunakan kolom gelas berdiameter 1,1 cm yang diisi dengan 4 gram resin jenis Dowex 50W-X8(Na). Umpan yang berupa larutan uranium berkadar 100 ppm dengan $\mathrm{pH}=4$ dan pengotor Ca serta Mg yang kadarnya bervariasi dari 25, 50, 75 dan 100 ppm dialirkan ke dalam kolom resin dengan pompa masterflex dengan kecepatan alir tetap 2,5 ml/menit. Kadar efluen uranium yang keluar dari kolom resin dianalisis menggunakan spektrofotometer dengan memakai arsenazo sebagai pengompleks. Dari data kadar U yang masuk dan keluar dari kolom resin dapat ditentukan nilai penurunan efisiensi kadar $U$. Dari data penelitian diperoleh bahwa nilai penurunan efisiensi pemisahan kadar U yang dicapai dengan pengotor Ca dari 99,1\% ke 92\% sedangkan untuk pengotor Mg dari 97,8 \% ke 94\%.
\end{abstract}

\section{ABSTRACT}

EFFECT OF Ca AND Mg IMPURITY SUBSTANCES ON THE EFFICIENCY OF DECREASINGURANIUM CONCENTRATION IN THE WASTE WATER. Study of uranium waste water treatment contained $\mathrm{Ca}$ and $\mathrm{Mg}$ impurity substances using ion exchange has been experimentally investigated. This experiment was conducted by the glass column of $1.1 \mathrm{~cm}$ diameter containing resin Dowex 50-X8(Na). Feed of $100 \mathrm{ppm}$ uranium solution at the $\mathrm{pH}$ of 4 with Ca and $\mathrm{Mg}$ impurities varied from 25, 50, 75 and100 ppm was flown into the column of resin using master flex pump at the constant flow rate of $2.5 \mathrm{ml} / \mathrm{min}$. The effluents concentration of uranium flowing out of columns resin were analyzed using spectrophotometer with arsenazo as the complexing agent. From the data of uranium concentration entering into and exiting from the column's resin could be determined the efficiency of minimization's value of uranium concentration. From the experimental data, the efficiency of minimization's value of uranium concentration obtained with the impurity of Ca from $99.1 \%$ to $92 \%$ while which the impurity of $\mathrm{Mg}$ from $97.8 \%$ to $94 \%$.

\section{PENDAHULUAN}

$\mathrm{P}$ engolahan air limbah yang mengandung uranium dengan memakai metoda pertukaran kation, merupakan salah satu alternatif pengolahan air limbah yang mengandung unsur radioaktif atau bahan nuklir. Upaya ini dilaksanakan dengan mempelajari sifat-sifat pertukaran ion yang dimiliki oleh masing-masing unsur yang menurut KUNIN R.(1) bergantung pada valensi, kadar umpan, suhu, potensial pertukaran gugus fungsional dari penukar ionnya seperti ion hidrogen dan ion hidroksilnya dan koefisien aktivitasnya.
Demikian juga adanya kation pesaing yang terdapat dalam umpan juga berpengaruh pada nilai efisiensi pertukaran kationnya, sehingga bisa berakibat turunnya nilai efisiensi pemisahan unsur yang diinginkan dari dalam air limbah. Di samping sifat/karakter dari bahan penukar ionnya juga sifat dari air limbahnya menentukan keberhasilan dari penerapan metode pcrtukaran ion dalam menurunkan kadar uranium yang terdapat dalam air limbah. BENEDICT. M.dkk. ${ }^{(2)}$ menyebutkan bahwa data yang menyangkut sifat kimia uranium dalam media cair, berada pada 
kondisi ionik atau berada pada tingkat oksidasi 3, 4, 5 dan 6. Dengan mengetahui kondisi ionik dari unsur uranium, akan memungkinkan untuk menciptakan kondisi sedemikian sehingga proses pertukaran ion untuk pengolahan air limbah yang mengandung uranium mencapai hasil yang maksimum. Mengingat bahwa adanya unsurunsur lain yang bersifat sebagai pesaing dalam proses pemisahan, meskipun dari potensial pertukaran ion $U$ secara teoritis lebih tinggi dari pada unsur $\mathrm{Ca}$ dan $\mathrm{Mg}$, tetapi keberadaan unsur pesaing tersebut berpotensi untuk menurunkan nilai efisiensi pemisahan U dari air limbah. Hasil yang diharapkan dari penelitian ini ialah, seberapa besar pengaruh $\mathrm{Ca}$ dan $\mathrm{Mg}$ dalam mereduksi efisiensi minimasi U dalam limbah U.

\section{TEORI}

Pertukaran ion merupakan salah satu metode yang sudah lazim dipakai di dalam proses pengolahan limbah cair yang mempunyai volume besar tetapi kandungan kation radioaktifnya dalam jumlah yang relatif kecil. Proses ini dapat dipakai untuk memisahkan aktinida yang berasal dari hasilhasil fisi, sehingga aktinida tersebut dapat di daur ulang atau dipekatkan menjadi limbah alfa yang kecil volumenya dan mudah disimpan. Afinitas dari resin penukar ion paling besar biasanya untuk ion-ion yang muatannya paling tinggi atau untuk ion-ion yang berbeda tetapi mempunyai muatan yang sama. Menurut KUNIN R.(1), BENEDICT, M. dkk. (2), dan CHAFFIN, G.R. dkk. ${ }^{(3)}$ pemisahan radionuklida $U$ dengan metode pertukaran kation dapat dijelaskan dengan mekanisme sebagai berikut:

Reaksi pertukaran kation :

$\mathrm{NaR}+\mathrm{M}^{+} \rightarrow \mathrm{MR}^{-}+\mathrm{Na}^{+}$

$\mathrm{HR}=$ resin penukar kation

$\mathrm{Na}^{+}=$kation yang ada dalam gugus fungsional

$\mathrm{M}^{+}=$kation logam yang akan dipertukarkan

Dengan mengingat sifat uranium dalam larutan mempunyai tingkat kestabilan ionik yang berbeda karena tingkat valensinya maka sebagai patokan untuk mengasumsikan reaksi yang terjadi antara penukar kation dengan radionuklida uranium dipakai tingkat valensi $U$ yang paling stabil. Secara sederhana reaksi yang terjadi antara resin penukar ion dengan spesies ionik $U$ dapat digambarkan sebagai berikut:

$2 \mathrm{NaR}+\mathrm{UO}_{2}^{++} \rightarrow \mathrm{UO}_{2} \mathrm{R}_{2}+2 \mathrm{Na}^{+}$

$2 \mathrm{NaR}+\mathrm{Ca}^{++} \rightarrow \mathrm{CaR}_{2}+2 \mathrm{Na}^{+}$

$2 \mathrm{NaR}+\mathrm{Mg}^{++} \rightarrow \mathrm{MgR}_{2}+2 \mathrm{Na}^{+}$

Menurut persamaan (2) sampai dengan (4) terlihat bahwa pertukaran ion $\mathrm{U}$ dalam bentuk ionik $\mathrm{UO}_{2}{ }^{++}$dengan kation $\mathrm{Na}$ dalam resin $\mathrm{NaR}$ bersaing dengan unsur $\mathrm{Ca}$ dalam $\mathrm{Ca}^{++}$dan $\mathrm{Mg}$ dalam $\mathrm{Mg}^{++}$sehingga hasil yang dinyatakan sebagai nilai efisiensi pemisahan $U$ akan dipengaruhi oleh besarnya nilai pertukaran ion Ca dan Mg. Besar pengaruh Ca dan Mg ini bisa dilihat dari penurunan nilai efisiensi pemisahan $\mathrm{U}$ dengan naiknya kadar $\mathrm{Ca}$ dan $\mathrm{Mg}$ dalam umpan air limbah yang mengandung unsur $\mathrm{U}$.

\section{TATA KERJA}

\section{Bahan yang digunakan}

Bahan limbah cair yakni larutan uranium dengan kadar awal $=100 \mathrm{ppm}$, Resin Dowex 50W-X8(Na) seberat 4 gr, Larutan garam $\mathrm{Ca}$ dan $\mathrm{Mg}$ dengan kadar dari 25-100 ppm yang difungsikan sebagai logam pengotor, Arzenazo dengan kadar 0,08\% sebanyak $4 \mathrm{ml}$ sebagai pengompleks pada analisis kadar umpan U pra olah dan residu pasca olah.

\section{Alat yang digunakan}

Alat proses seperti kolom gelas dengan diameter kolom 1,1 cm, pompa dosis Masterflex diatur dengan debit 2,5 $\mathrm{ml} / \mathrm{men}$. Rangkaian skematis dari alat proses yang dipakai dalam percobaan ini dapat dilihat pada gambar 1 . 


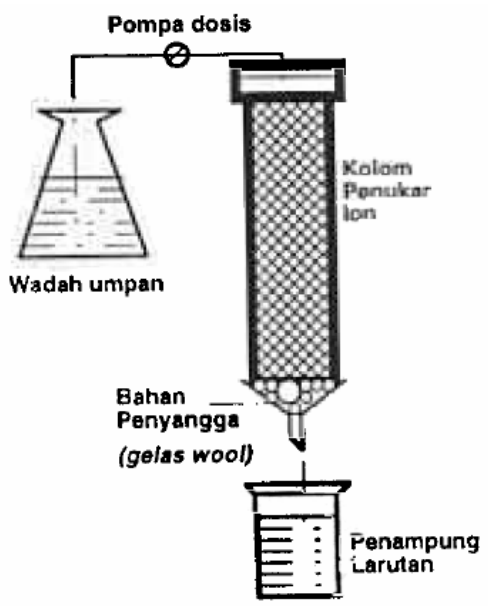

Gambar 1. Skema Alat Proses

Alat analisis/alat cacah seperti alat analisis spektrofotometer merk Spectronic 20, timbangan elektrik Sartorius dengan ketelitian $10 \mu \mathrm{g}$, kertas $\mathrm{pH}$ universal, alat-alat gelas seperti gelas beker, labu ukur, pipet pindah

\section{Metode Penelitian}

\section{Penyiapan larutan limbah Uranium}

Larutan limbah uranium yang digunakan dalam penelitian ini limbah simulasi menggunakan serbuk uranil nitrat $\mathrm{UO}_{2}\left(\mathrm{NO}_{3}\right) \cdot 6 \mathrm{H}_{2} \mathrm{O}$ yang dilarutkan dengan akuades sehingga kadarnya $=100 \mathrm{ppm}$.

Percobaan tanpa pengaruh pengotor Ca \& $\mathrm{Mg}$ terhadap efisiensi minimisasi kadar $U$

Resin Dowex 50W-X8(Na) sebanyak 4 gram, didekantasi dengan air bebas mineral kemudian dimasukkan ke dalam kolom gelas dengan ukuran diameter kolom 1,1 cm dan selanjutnya dialiri dengan larutan uranium berkadar 100 ppm. Kecepatan aliran larutan $\mathrm{U}$ kedalam kolom dengan bantuan pompa master flex tersebut diatur supaya tetap $=2,5$ $\mathrm{ml} /$ menit. Setiap30 menit keluaran larutan uranium dari kolom (efluen) ditampung dan dianalisis kadar U-nya untuk menghitung fraksi yang terjerap ke dalam kolom yang dinyatakan dalam nilai $\mathrm{EP}_{\mathrm{U}}$.
Percobaan pengaruh pengotor $\mathrm{Ca}$ terhadap efisiensi minimisasi kadar $U$

Resin Dowex 50W-X8(Na) sebanyak 4 gram, didekantasi dengan air bebas mineral kemudian dimasukkan ke dalam kolom gelas dengan ukuran diameter kolom 1,1 cm dan selanjutnya dialiri dengan larutan uranium berkadar $100 \mathrm{ppm}$ yang telah ditambah senyawa Ca dengan kadar yang divariasi dari 25 -100 ppm. Kecepatan aliran larutan U ke dalam kolom dengan bantuan pompa master flex tersebut diatur supaya tetap $=2,5$ $\mathrm{ml} /$ menit. Setiap 30 menit keluaran larutan uranium dari kolom (efluen) ditampung dan dianalisis kadar U-nya untuk menghitung fraksi yang terjerap ke dalam kolom yang dinyatakan dalam nilai $\mathrm{EP}_{\mathrm{U}}$.

Percobaan pengaruh pengotor $\mathrm{Mg}$ terhadap efisiensi minimisasi kadar $U$

Resin, Dowex 50W-X8(Na) sebanyak 4 gram setelah didekantasi dengan air bebas mineral kemudian dimasukkan ke dalam kolom gelas dengan ukuran diameter kolom 1,1 cm dan selanjutnya dialiri dengan larutan uranium berkadar100 ppm yang telah ditambah senyawa Mg dengan kadar yang divariasi dari 25 -100 ppm. Kecepatan aliran larutan U ke dalam kolom dengan bantuan pompa master flex tersebut diatur supaya tetap $=2,5 \mathrm{ml} /$ menit. Setiap 30 menit keluaran larutan uranium dari kolom (efluen) ditampung dan dianalisis kadar U-nya untuk menghitung fraksi yang terjerap ke dalam kolom yang dinyatakan dalam nilai $\mathrm{EP}_{\mathrm{U}}$.

\section{HASIL DAN PEMBAHASAN}

\section{Percobaan tanpa pengaruh pengotor Ca \& Mg terhadap efisiensi minimisasi kadar U}

Hasil percobaan tanpa pengaruh pengotor $\mathrm{Ca} \& \mathrm{Mg}$ terhadap efisiensi minimasi kadar $U$ dapat dilihat pada Gambar 2 dan Gambar 3. Terlihat bahwa 
efisiensi pemisahan uranium $\left(\mathrm{EP}_{\mathrm{U}}\right)$ mencapai $99,6 \%$.

\section{Percobaan pengaruh pengotor $\mathrm{Ca}$ terhadap efisiensi minimisasi kadar $\mathrm{U}$}

Hasil percobaan pengaruh pengotor $\mathrm{Ca}$ terhadap efisiensi minimasi kadar $U$ dapat dilihat pada Gambar 2. Terlihat bahwa keberadaan unsurCa dengan kadar lebih besar dari pada 25 ppm cenderung untuk menurunkan efisiensi pemisahan uranium $\left(\mathrm{EP}_{\mathrm{U}}\right)$ ke $\mathrm{EP}_{\mathrm{U}}$ yang lebih rendah dari pada 99,1 \%. Hal ini disebabkan karena adanya Ca yang bervalensi 2 akan aktif menjadi pesaing pada pertukaran kation $\mathrm{UO}_{2}^{++}$, sehingga kemampuan berkompetisi untuk melakukan proses pertukaran ion menurun yang dapat dilihat dari penurunan $\mathrm{EP}_{\mathrm{U}}$ dalam hasil proses pertukaran ion dari 99,1 \% menjadi $92 \%$.

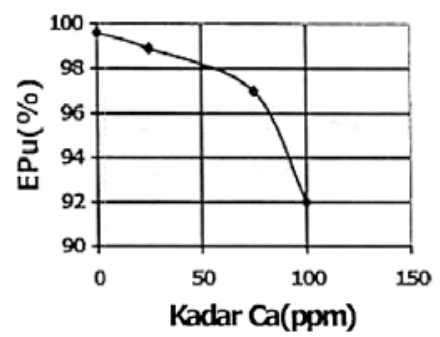

Gambar 2. Kurva Hubungan kadar Ca (ppm) lawan $\mathrm{EP}_{\mathrm{U}}(\%)$

\section{Percobaan pengaruh pengotor $\mathrm{Mg}$ terhadap efisiensi minimisasi kadar $U$}

Hasil percobaan pengaruh pengotor $\mathrm{Mg}$ terhadap efisiensi minimasi kadar $\mathrm{U}$ dapat dilihat pada Gambar 2. Terlihat bahwa keberadaan unsur $\mathrm{Mg}$ dengan kadar lebih besar dari pada 25 ppm cenderung untuk menurunkan efisiensi pemisahan uranium $\left(\mathrm{EP}_{\mathrm{U}}\right)$ ke EP yang lebih rendah dari pada 97,1\%. Hal ini disebabkan karena adanya $\mathrm{Mg}$ yang bervalensi 2 akan aktif menjadi pesaing pada pertukaran kation $\mathrm{UO}_{2}{ }^{++}$, sehingga kemampuan berkompetisi untuk melakukan proses pertukaran ion menurun yang dapat dilihat dari penurunan $\mathrm{EP}_{\mathrm{U}}$ dalam hasil proses pertukaran ion dari 97,8\% sampai dengan $94 \%$.

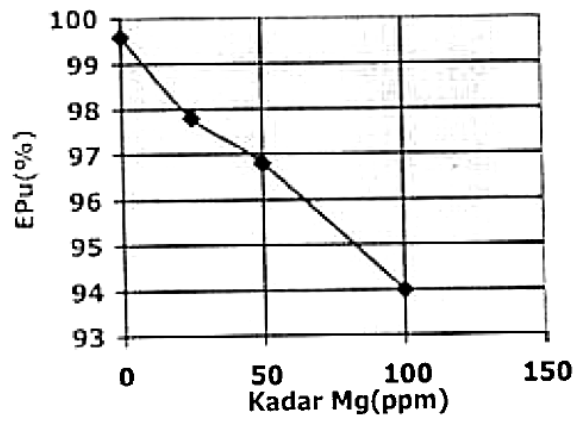

Gambar 3. Kurva hubungan kadar Mg (ppm) lawan $\mathrm{EP}_{\mathrm{U}}(\%)$

\section{KESIMPULAN}

Kesimpulan yang dapat ditarik dari hasil penelitian ini ialah bahwa:

1. Efisiensi minimasi kadar uranium tanpa pengotor $\left(\mathrm{EP}_{\mathrm{U}}\right)=99,6 \%$ relatif lebih besar dari pada $\left(\mathrm{EP}_{\mathrm{U}}\right)$ dengan adanya unsur pengotor $\mathrm{Ca}$ dan $\mathrm{Mg}$.

2. Efisiensi minimasi kadar uranium $\left(\mathrm{EP}_{\mathrm{U}}\right)$ menurun dengan bertambahnya kadar unsur pengotor Ca yang terdapat di dalam larutan umpan U dari 99,1\% sampai dengan $92 \%$.

3. Efisiensi minimasi kadar uranium $\left(\mathrm{EP}_{\mathrm{U}}\right)$ menurun dengan bertambahnya kadar unsur pengotor $\mathrm{Mg}$ yang terdapat di dalam larutan umpan $\mathrm{U}$ dari 97,8\% sampai dengan 94\%.

\section{UCAPAN TERIMA KASIH}

Penulis mengucapkan terima kasih yang sebesar-besarnya atas penyelesaian eksperimen yang telah dilakukan oleh Sdr. Muh. Ribhan Sulistyo Hadi, sehingga penulisan makalah ini bisa terwujud.

\section{DAFTAR PUSTAKA}

1. KUNIN, R. AND MYERS, R.J., "Ion Exchange Resin, John Wiley and Sons Inc", New York (1950).

2. BENEDICT, M., PIGFORD, T.H. AND LEVI,H.W. "Nuclear Chemical 
Engineering" McGraw-Hill Book

Company, USA (1981).

3. CHOPPIN, G.R. AND RYDBERG, J. "Nuclear Chemistry Theory and

Application", Pergamon Press, Toronto (1980). 